SER SOCIAL 6

\title{
A (nova) questão social e as estratégias para seu enfrentamento
}

ROSA HELENA STEIM

\section{Apresentação}

A definição da temática do presente trabalho levou em consideração o debate que tem sido travado, internacionalmente, sobre as controvérsias do processo de globalização e as consequências sociais desse processo, tais como: crescentes índices de desemprego estrutural e pobreza, acompanhados do fenômeno da exclusão social, identificado por alguns como uma "nova questão social".

Para o seu enfrentamento, diversas têm sido as estratégias adotadas pelos governos. No entanto, interessa-nos focalizar a estratégia da descentralização político-administrativa, buscando aprofundar a discussão sobre o "pluralismo de bem-estar", como alternativa "pós-moderna" à chamada crise do Estado Providência.

O trabalho compreende dois momentos. No primeiro, buscamos contextualizar a emergência da questão social, gerada pelas grandes transformações sociais, políticas e econômicas produzidas pela revolução industrial, bem como a origem de um novo tipo de regulação, com base no direito do cidadão e no dever do Estado - o Estado de Bem-Estar.

Assistente Social, mestre em Política Social/UnB, professora do Departamento de Serviço Social/UnB, aluna do Programa de Doutorado do Centro de Pesquisa e Pós-Graduação para América Latina e Caribe - CEPPAC/ICS/UnB 
NO segundo, buscamos problematizar a crise/reestruturação do Estado de Bem-Estar, num período marcado por grave crise econômica e acentuada crítica de setores conservadores. Situamos, a partir daí, a "nova questão social", bem como as políticas de bem-estar pluralistas, como forma de enfrentamento desta questão, para a qual converge um padrão de proteção social que favorece à dualização e domínio do setor privado.

\section{A contextualização da questão social}

\section{O surgimento e os desafios postos pela questão social}

A "questão social" assim nomeada pela primeira vez por volta de 1830 , tem origem na Europa, a partir das grandes transformações sociais, políticas e econômicas advindas da revolução industrial. Tem como fundamento o reconhecimento de um conjunto de novos problemas vinculados às modernas condições de trabalho urbano. Assim, conforme Castel (1998), "questão social" configura-se, a partir da "tomada de consciência das condições de existência das populações que são, ao mesmo tempo, os agentes e as vítimas da revolução industrial" (p.30). Mas, este é um período que torna evidente não só o pauperismo, como também a lacuna entre a organização política e o sistema económico. Esta lacuna torna-se o espaço possível a ser ocupado pelas "franjas mais dessocializadas dos trabalhadores" na sociedade industrial e, em resposta a ela, busca-se a sua integração social.

Em que pesem os dispositivos adotados para a citada integração, tendo como referência a "questão social", o social ${ }^{2}$ já estava presente nas sociedades pré-industriais da Europa Ocidental, e inúmeras foram as maneiras institucionalizadas de perfil não-mercantil de regular distintas categorias de indigentes. Havia não só um modelo que Castel denominou "social-assistencial" ${ }^{3}$, mas também uma intervenção pública que ia da

2 Considerado como um sistema de regulações que deverá servir de contraponto à lógica de rentabilidade excludente no mercado (Pereira, 1999).

3 Práticas que visam, de maneira organizada, a suprir as carências da sociabilidade primária, definida por Castel como "sistema de regras que ligam diretamente os membros de um grupo a partir de seu pertencimento familiar, da vizinhança, do trabalho e que tecem redes de interdependência sem a mediação de instituições específicas" (p.48) 
assistência aos indigentes à repressão da vagabundagem, bem como a participação do Estado desempenhando o "papel de fiador de manutenção da organização do trabalho e de regulador da mobilidade dos trabalhadores" (p 31).

Portanto, a existência da pobreza nem sempre foi considerada um "problema". Nas sociedades pré-industriais, era considerada um fenômeno natural e necessário, no sentido de tornar os pobres laboriosos e úteis à acumulação de riquezas das nações em formação. Mas, com as novas tensões sociais decorrentes da industrialização, ela passou a ser considerada uma "ameaça à ordem política e moral", tornando-se, portanto, um problema a ser enfrentado e resolvido. A "questão social", conforme Castel, "pode ser caracterizada por uma inquietação quanto à capacidade de manter a coesão de uma sociedade" (p.41).

Assim, no contexto da industrialização, a questão social apresentase não só com desafios colocados pela nova ordem, como também com a emergência de novos atores e conflitos. Esta difere, portanto, da questão social da fase precedente por constituir um novo tipo de regulação social - com base no "direito do cidadão e dever do Estado".

Essa transformação foi marcada por intensas lutas entre as forças liberais, cujos princípios centravam-se na noção de mercado auto-regulado, e as forças protecionistas, com base nos princípios de amparo social materializados em uma legislação protetora.

Portanto, foi de fundamental importância o papel que os interesses de classe jogaram nesse movimento, principalmente as pressões da classe operária, organizada em sindicatos e em partidos políticos, não só articulando denúncias relativas à situação dos pobres, como também formulando propostas para o enfrentamento da questão (Gomes, 1979).

Assim, os avanços da industrialização e as pressões por um sistema político mais democrático, no sentido de rompimento com a tradicional concepção de proteção/dependência e a emergência de idéias sobre novos direitos sociais, marcam o conteúdo e a expressão das políticas sociais, a partir do século XLX. Como resultado deste processo destacam-se algumas medidas: Sistema de Seguridade Social de Bismarck, em 1880; Sistema de desemprego de Lloyd-George, de 1911; a melhora e a extensão dos 
benefícios da seguridade social italiana, em 1969; a introdução do Serviço Nacional de Saúde e de Educação Gerai na Inglaterra.

Ian Gough (1982) ressalta que muitas são as formas pelas quais a pressão social gera medidas para o aumento do bem-estar, desde aquelas cujo resultado advém de uma ação de massas - como na França depois de maio de 1968 e na Itália depois do "otono caliente" de 1969 -, até às idealizadas peíos representantes da classe dirigente, com o objetivo de evitar ampliação de movimentos de trabalhadores. Gough considera um exemplo desta tática a Seguridade Social de Bismark.

De acordo com Gough (1982), a criação de um proletariado e a relativa autonomia do Estado capitalista foram a causa da chegada da democracia liberal nos países avançados (idem, p. 136). Considera, ainda, este autor, que um marco importante para a compreensão do crescimento dos direitos políticos e sociais e, daí ao Estado de Bem-Estar social, localiza-se no conflito de classes em desenvolvimento sob o capitalismo monopolista. Mas, alerta que somente o conflito de classes não é suficiente para justificar as origens e o desenvolvimento do Estado de Bem-Estar, tornando-se necessário explicar, também, como são formulados e implementados os interesses da classe dominante, isto é, por quais mecanismos os interesses são mediados e articulados pelo Estado.

\section{Origem, conceituação e desenvolvimento do Estado de Bem- Estar}

Entre os vários estudos ${ }^{4}$ sobre o fenômeno do Welfare State, existem abordagens distintas sobre a sua emergência, considerando $o s$ diferentes enfoques teóricos utilizados para a sua definição. Na análise de diversas produções, realizada por Fleury (Í994), destacam-se enfoques sobre a emergência do Welfare State, que o relacionam: à Primeira Guerra Mundial (Titmuss); ao contexto de guerra para justificar o consenso criado (Marshall e Beveridge); às condições e grau de mobilização da classe trabalhadora (Esping-Andersen); ao processo de desenvolvimento das sociedades capitalistas industrializados (Flora, Heidennheimer e Alber), e ao conflito de classes e ao crescimento da classe trabalhadora (Gough).

\footnotetext{
${ }^{4}$ Ver Fleury (1994). A autora analisa as diferentes produções sobre a temática.
} 
Para Gough, a origem do Estado de Bem-Estar foi um fenômeno geral do pós-guerra, como parte de um acordo entre o capital e o trabalho e de uma estrutura estatal mais intervencionista. O papel desenvolvido pelo Estado durante a Segunda Guerra - a expansão da socialização da produção e novo equilíbrio internacional de forças - constituiu um fator importante. Em todos os países houve aumento da intervenção estatal na economia e acentuada importância do papel do Estado na multiplicação de políticas de bem-estar.

\section{O que é o Welfare State?}

Inicialmente é preciso ultrapassar o simplismo da usual definição de que o Welfare State envolve responsabilidade estatal na garantia de bemestar do cidadão, já que não se tem clareza se as políticas garantidoras desse bem-estar são emancipatórias ou não; se contradizem ou ajudam o mercado; e a que tipo de necessidades atendem - básicas ou mínimas?

"O Welfare State não pode ser compreendido apenas em termos de direitos e garantias. É preciso levar em consideração a forma de entrelaçamento das atividades estatais com o papel do mercado e da família em termos de provisão social" (Esping-Andersen, 1991).

E preciso, ainda, fazer uma distinção entre a instituição Estado de Bem-Estar Social (Welfare State) e o processo denominado bem-estar social (social Welfare), como nos alerta Pereira (1994a:4). "O Welfare State é a intenção institucionalizada de promover bem-estar de todos os membros de uma dada sociedade enquanto o Social Welfare é o efetivo bem-estar usufruído pela sociedade seja mediante as políticas do Welfare State ou de outras instituições" (idem). Sendo assim, não há um modelo único de Welfare State, já que seu funcionamento varia de um contexto nacional para outro.

Deve-se distinguir também a política social do Estado de BemEstar ou Welfare State. De acordo com Mishra, também analisado por Pereira (idem), a política social (social policy) é um conceito genérico, enquanto o Welfare State tem conotação histórica (o pós-Segunda Guerra Mundial) e institucional (o Estado capitalista regulador e provedor de 
benefícios, serviços sociais, de inspiração keynesiana). A política social, portanto, antecede o pós-Segunda Guerra e vem sendo desenvolvida historicamente sob diferentes tipos de relação entre Estado e sociedade, bem como sob diferentes formas de regulação. Já o Welfare State é uma instituição do século XX, cuja construção "dependeu da edificação de coalizões políticas" (Esping-Andersen, p. 112), e foi "caracterizado por um tipo de relação entre Estado e sociedade antes inexistente", ancorada em princípios que priorizam os seguintes objetivos:

- extensão dos direitos sociais;

- oferta universal de serviços sociais;

- preocupação com o pleno emprego;

- institucionalização da assistência social como rede de defesa contra a pobreza absoluta e meio de garantir a manutenção de padrões mínimos de atenção às necessidades básicas (Pereira, 1994a:3).

A distinção entre as políticas sociais do Welfare State e a políticas sociais das Leis dos Pobres, instituídas na Inglaterra desde o século XVII, incide na identificação com o conceito de cidadania na primeira situação e a ausência de garantia de direitos na segunda.

Buscando, então, definir o Welfare State, Fraser o compreende como "um sistema de organização social que procura restringir as livres forças do mercado em três principais direção: a) garantindo direitos e segurança social a grupos específicos da sociedade, como crianças, idosos e trabalhadores; b) distribuindo de forma universal serviços sociais como saúde e educação; c) transferindo recursos monetários para garantir a renda dos mais pobres em certas contingências, como a maternidade, ou em situações de interrupção de ganhos devido a fatores como doença e desemprego (ap ud Pereira, idem).

Entretanto, a intervenção do Estado nas referidas direções só vai se dar a partir de determinada conjuntura política e econômica, que compreende os seguintes acontecimentos: a Segunda Guerra Mundial; a prosperidade econômica do pós-guerra; o surgimento do fascismo; a ameaça do comunismo; o fortalecimento da classe trabalhadora. 
Assim, apesar dos princípios públicos que orientam o Welfare State, ele é, segundo Offe (1991), "historicamente a combinação resultante de uma série de fatores, cuja posição varia de país a país [...]. É justamente o seu caráter multifuncional e a sua capacidade de servir, concomitantemente, a múltiplos objetivos, que tomam a organização política do Estado Social tão atrativo para uma ampla coligação de forças heterogêneas" (p. 115).

Offe (1991) destaca, portanto, assim como Gough, o caráter contraditório do Welfare State. Para ele, "e/ Estado delBienestar exhibe rasgos positivos y negativos dentro de una unidade contradictoria. Ínevitablemente refleja la contradicción de las raices de la sociedad capitalista: entre las fuerzas de producción y las relaciones de producción" (p.63).

Verifica-se que além de ser um "fenômeno contraditório", o Welfare State também não se constitui em um modelo único. Modelos foram apresentados porTitmuss, ${ }^{5}$ Goran Therborn, Gosta Esping-Andersen, Ascoli, entre outros, sendo que o de Titmuss (residual, industrial e institucional redistributivo) tem sido referência, conforme Pereira, para todos os demais.

A classificação de Therborn (1989:86) leva em consideração o nível de reconhecimento dos direitos sociais e a orientação para o mercado e pleno emprego. Apresenta quatro tipos de Welfare States:

1- Estados de bem-estar intervencionistas fortes: aqueles com presença decisiva do Estado, cuja intervenção prioriza a universalização das políticas sociais e o compromisso com o pleno emprego.

2- Estados de bem-estar compensatórios brandos: aqueles com reconhecimento de direitos sociais, porém, políticas de caráter compensatório, baixo comprometimento com o pleno emprego.

3- Estados orientados ao mercado com escassa política de bemestar: voltados para o mercado com baixo nível de reconhecimento de direitos e com o pleno emprego.

\footnotetext{
É de Titmuss "a mais antiga e ainda útil especificação de tipos de bem-estar"- Bem-estar social, bem-estar fiscal e bem-estar ocupacional (Cf.Pereira, 1994a:5)
} 
4- Estados orientados ao pleno emprego com escassa política de bem-estar: aqueles com baixo nível de reconhecimento de direitos mas com certo compromisso institucional com o pleno emprego.

Esping-Andersen ${ }^{6}$ (1991), por sua vez, apresenta três modelos agrupados de acordo com os tipos de regime: "liberal", conservador e "social-democrata".

1. Welfare State "liberal": predominância da assistência aos comprovadamente pobres e prevalência da lógica do mercado.

2. Welfare States conservadores e fortemente "corporativistas": predominância da subordinação dos direitos à classe e ao status. O Estado é subsidiário de outras instituições, em especial, a Igreja (comprometimentos com a preservação da família tradicional).

3. Welfare State "social-democrata": o Estado é o principal promotor da igualdade; prevalência de programas desmercadorizantes e universalistas; presença de uma solidariedade universal - "todos se beneficiam; todos são dependentes; e supostamente todos se sentirão obrigados a pagar" (p. 110).

Há, ainda, a tipologia elaborada por Ascoli ${ }^{7}$, a qual estreitamente referenciada em Titmus, apresenta os seguintes tipos de Welfare: residual, meritocrático-particularista e institucional-redistributivo.

Por conseguinte, se há modelos diferenciados, torna-se importante a identificação quanto à predominância ou não de algum deles. Antes de tal identificação, é importante destacar que dos anos 40 até os 70 o Estado Social "serviu como a mais importante fórmula de paz para as democracias capitalistas desenvolvidas", que consiste na obrigação explícita do mecanismo estatal de proporcionar assistência e apoio aos cidadãos, e "baseia-se no reconhecimento do papel formal dos sindicatos tanto nas negociações coletivas entre o capital e o trabalho quanto no processo de formação da vontade política" (Offe, 1991:113).

${ }^{6} \mathrm{O}$ autor alerta para a importância de não se fazer comparações tendo em vista que, apesar de formarem um grupo, "não existe um único caso puro" (1991:110).

7 Cf. Draibe (1990). 
Esse sistema guiou-se por três doutrinas que, combinadas, formam o que Pereira (1994b:5), inspirada em Roche (1992), vem chamando de "paradigma dominante do Estado de bem-estar", amparadas: a) no receituário keynesiano de regulação econômica e social; b) nas recomendações de William Beveridge sobre seguridade social, e c) na teoria da cidadania de T.H. Marshal.

Esta "fórmula" política foi reconhecida pelas elites tanto dos países onde o Estado Social estava consolidado, como a Grã-Bretanha e a Suécia, quanto daqueles onde não estava inteiramente realizado como nos Estados Unidos, até meados dos anos 70. A partir de então, esta mesma "fórmula da paz" tornou-se objeto de dúvida, de crítica profunda e de conflito político; passou a ser fonte de contradições e antagonismos. "A própria mecânica do compromisso das classes se converteu em objeto de conflitos entre elas" (Offe, 1991:115), provocando mudanças profundas no padrão de intervenção.

Essas mudanças poderiam ser caracterizadas por meio de duas interpretações sobre o futuro do Welfare State: uma, que o considera esgotado, incapaz de responder aos desafios de hoje. Outra, que o vê em transformação, e não propriamente em crise, isto é, em reestruturação, tendo em vista os novos desafios estruturais e ideológicos, provocados pelas mudanças ocorridas nos âmbitos da economia e da sociedade. Por esta interpretação (Gough apud Pereira, 1994), "se há crise, ela pode ser identificada com os percalços sofridos pelo paradigma dominante de cidadania social ou de provisão social baseado no esquema KeynesBeveridge".

Este período é marcado, segundo Gough, por uma crise sem precedentes na economia capitalista mundial, representando, desde o final de 1973 a 1975, um retrocesso sem paralelo no período do pós-guerra, como:

- diminuição em 5\% do PNB dos países da OCDE;

- declínio da produção industrial;

- aumento de desemprego, atingindo 15 milhões de desempregados no conjunto dos países da OCDE; 
- déficit comercial coletivo cada vez maior no mundo capitalista avançado.

Para Gough, a manifestação mais visível da crise no setor estatal estava na enorme diferença entre receita e despesa, levando ao endividamento do setor público.

Esta "fotografia" da "crise" fez com que forças políticas, tanto à direita quanto à esquerda se manifestassem e passassem a exigir mudanças nos métodos, no conteúdo e nos objetivos do Welfare State.

Esta fase corresponde a um dos períodos da história do Estado Sociai do pós-guerra, conforme periodização feita por Mishra (1995:91) e Pereira (1992).

1- Pré-crise: abrange o período 1950-1975, durante o qual firmouse o Welfare State como paradigma dominante e estável do desenvolvimento social no Ocidente. Diversos foram os fatores que conformaram o contexto de emergência do Welfare State, podendo destacar-se os seguintes:

- a depressão econômica e o desemprego em massa nos anos 30;

- a Segunda Guerra Mundial;

- a prosperidade econômica do pós-guerra;

- o surgimento do facismo;

- a crescente ameaça do comunismo.

O período é marcado por uma nova interação entre capital e trabalho e entre capitalismo e democracia, propiciando uma ampla garantia de direitos sociais.

2- Crise: o período de 1975-1980 é marcado pelo desequilíbrio do capitalismo assistencial, acarretando uma crise de confiança na viabilidade do Estado keynesiano.

3- Pós-crise: o período que teve início por volta de 1980, com ascensão dos governos Thatcher (Inglaterra) e Reagan (Estados Unidos) sob um programa que propunha uma ruptura ideológica com o Welfare State de orientação keynesiana/beveridgiana/marshalliana. Surgem como 
abordagens alternativas o neoconservadorismo, à direita - cuja política representa um regresso à sociedade dual do passado -, e o socialcorporativismo com empenho para manutenção dos três elementos básicos do Welfare State, do pleno emprego, serviços sociais universais e a manutenção de um nível mínimo básico, adaptando-se ao novo "quadro de uma economia de mercado de propriedade privada e orientada para o lucro" (idem, p.92).

Neste contexto, os eixos considerados precondições ao funcionamento do Welfare State (Estado-Nação soberano, sindicatos fortes, relações de trabalho bem definidas e institucionalizadas e salários amparados legalmente), bem como o pleno emprego, como o fio condutor do processo econômico e político, já não mais o sustentavam. A globalização da economia é a tendência que substituiu as referidas precondições, caracterizada por novos mercados, instrumentos, atores e regras.

Na análise de Offe (1989) esta é a era do capitalismo desregulado ou desorganizado, impondo-se a exigência de novas regras e novas modalidades de relação no âmbito do trabalho. A produção industrial é invadida pela alta tecnologia, e já não precisa mais do mesmo número de trabalhadores na indústria, os quais são absorvidos pela terceirização ou jogados no desemprego. Diante desta nova realidade os trabalhadores buscam a sobrevivência no chamado "trabalho flexível", como uma imposição, assumindo uma variedade de funções precárias ou submetendose a diferentes regimes desprotegidos de trabalho.

\section{Crise ou reestruturação do Welfare State?}

É certo que, como afirma Pierson (1991), "desde 1975 a festa do crescimento acabou e a expansão das políticas do Welfare State tem sido severamente restringida...". Contudo, para Gough o que ocorre não é um desmantelamento e sim, sua reestruturação, ou mudanças de seus valores básicos, considerando a quebra de compromissos com os três pilares que o sustentavam. 
Parece consenso, entre os estudiosos da questão do Estado, a idéia de que a última década tem sido dominada por forte ofensiva das teses neoliberais, hegemônicas na condução das políticas públicas. Há controvérsias $^{8}$ quanto à análise de seus efeitos; no entanto, Manuel Castells considera que "el efecto real de dichas ideas ha sido relativamente limitado en los sistemas de laprotección social" (1997:179). Por isso, afirma que nem a administração Thatcher no Reino Unido, nem a administração Reagan nos Estados Unidos conseguiram reduzir substancialmente o gasto social apesar dos esforços na privatização. Dupas problematiza também a questão ao apresentar a "provocação" contida em ensaio publicado em The Economist (1997) "Quem disse que a era dos grandes governos terminou!". Estudos constatam que "em todas as economias avançadas, os gastos do Governo têm crescido, e rapidamente [...] Ao que tudo indica os Estados nacionais continuam não somente gastando muito como endividando-se crescentemente para pagar estes gastos" (1999:89). Dupas apresenta, ainda, dados analisados por Jean-Pierre Dumond, os quais revelam que "em todos os países da Europa ocorreu, como proporção do PIB, acentuado aumento das despesas de proteção social desde os anos 70 até 1992" (idem).

Da mesma forma, as análises do Banco Mundial revelam semelhantes tendências. Contudo, afirma Gough "de lo que ahora somos testigosno es tanto de un recorte en el gasto total del Estado [...], sino su reestructuración en direcciones específicas" (1982:232).

Se os dados indicam que as despesas de proteção social na Europa, nos Estados Unidos ou no Japão não foram reduzidas, e que os gastos públicos na maioria dos países do mundo aumentam, por outro lado o discurso desestatizante tem sido uma "palavra de ordem". Com ele, vinculam-se as soluções capazes de resolver os seguintes problemas: de estrangulamento do setor público - a redução das dimensões do Estado; de enfrentamento do desemprego - a flexibilização do mercado de trabalho.

Entretanto, Manuel Castells considera que "Lo que no es evidente es que la consequencia de dicha crisis sea el desmantelamiento del

${ }^{8}$ Esping-Anderscn, ao analisar um grupo de países que adotaram estratégias de desregulamentação orientadas para o mercado, apesar de não se manifestarem uniformemente, "o aprofundamento da desigualdade e o crescimento dos níveis de pobreza são comuns aos casos liberais" (1995:91). 
Estado del Bienestar, como pretenden las tesis neoliberalis" (1997:. 179). Para ele, é possível conceber formas alternativas de reforma que mantenham o direito do cidadão, a proteção social. Porém, considera fundamental, primeiramente, reconhecer a crise estrutural do Estado de Bem-Estar e identificar suas causas.

A crise, a seu ver, consiste em três aspectos:

a) crise das finanças públicas;

b) crise de competividade econômica;

c) crise de legitimidade.

Se nestes três aspectos reside a crise, as suas causas resultam da convergência de quatro processos:

$1^{o}$. A deterioração da relação entre contribuintes e beneficiários dos sistemas de proteção social resultante das tendências demográficas, culturais e econômicas

Os problemas de financiamento do Estado de Bem-Estar são provenientes da carga crescente das pensões e dos gastos com saúde, principalmente com os "velhos". A baixa taxa de fertilidade, combinada com o envelhecimento da população, irá gerar altas taxas de dependência, sem o correspondente crescimento econômico. A proporção de dependentes na Comunidade Européia crescerá de $50 \%$ de hoje até 2020, o que absorverá um adicional de 5\% a 7\% do PIB. Até 2040, projeções da OCDE indicam que o envelhecimento dobrará ou triplicará os gastos com aposentadorias e saúde (Esping-Andersen, 1995:79).

Um dos grandes desafios para o futuro será o de "uma sociedade em que os idosos estão mais garantidos quanto ao futuro do que os jovens" (Castel, 1998:570), tendo em vista que ainda "se beneficiam das proteções montadas pela sociedade salarial" (idem). Neste sentido, "o principal problema não é demográfico e sim, econômico e de estrutura de emprego" (Castells, 1997:181).

$2^{\circ}$. A crescente diversificação e segmentação da sociedade

O modelo de produção desenvolvido no capitalismo organizado 
(o modelo de produção "fordista") teve como consequência a homogeneização das condições de trabalho, salário e estilo de vida da população. Como assinala Castells, o "homem da organização" tinha um ciclo de vida ocupacional, previsível e pautado, enquanto a reorganização tecnológica e econômica tem provocado profunda segmentação da sociedade. Há, de um lado, uma transformação da estrutura ocupacional provocada pela polarização entre trabalhos altamente qualificados e trabalhos sem qualificação. De outro, a acelerada mudança tecnológica e o surgimento de redes de empresas como estratégia mais dinâmica de organização econômica tem provocado uma mudança contínua da atividade profissional, cuja marca é a imprevisibilidade e a individualização.

Desta forma, a homogeneização e socialização das condições de trabalho e de consumo têm sido substituídas pela fragmentação e a diversificação profissional e do ciclo de vida.

Considerando que as instituições do Estado de Bem-estar tinham o conjunto da população como beneficiários, agora, este conjunto diversificase, provocando uma "especialização" cada vez maior nos grupos mais desfavorecidos, que acabam por receber proporção maior de recursos em contraposição aos grupos sociais mais elevados. Tal postura contribui para o esgarçamento dos laços de solidariedade intra e intergeracional. Diante da imprevisibilidade e incertezas, a busca de solução dos problemas se dá em nível cada vez mais individual.

\section{$3^{\circ}$. Crescente hegemonia do individualismo no sistema de valores}

Em sociedades cada vez mais competitivas, o projeto individual aparece como a forma privilegiada de realização pessoal.

A crise das organizações de solidariedade, o declínio das ideologias políticas progressistas e a crise da família patriarcal têm concorrido para o fortalecimento do indivíduo "como centro de los processos de acumulación de riqueza, poder y deseo" (Castells, p.183). Nesta perspectiva, o Estado de Bem-Estar perde legitimidade e os mecanismos de solidariedade "aparecem como un refugio para los perdedores del sistema" (idem). 
$4^{o}$. A formação de uma economia global como unidade de atuação fundamental dos agentes econômicos altera a estrutura da competência entre empresas, países e regiões.

Como analisa Dupas, as empresas transnacionais contemporâneas não são mais estruturas verticalizadas; caracterizam-se, agora, pela fragmentação e dispersão do processo de produção por várias nações, por meio de filiais e de fornecedores ou subcontratados (p.14). Tais empresas, além de fabricarem diferentes partes do produto em diferentes países, seguem contratos de trabalho variados.

As referidas estratégias reduzem a base de emprego e, consequentemente, agravam a crise do Estado de Bem-Estar.

Diante deste quadro, de crise para alguns e reestruturação para outros, quais os reflexos para o conjunto da sociedade?

\section{Uma "nova" questão social?}

O mundo político e econômico vem se defrontando, nas duas últimas décadas, com abundantes sinais e marcas de modificações radicais em processos de trabalho, hábitos de consumo, configurações geográficas e geopolíticas, poderes e práticas do Estado etc, conforme afirma Harvey (1993:117). Estaria este quadro configurando uma "nova questão social"? Este contexto tem sido motivo de estudos, pesquisas, discussões, resultando em importantes publicações, dentre as quais destacamos A nova questão social, de Pierre Rosanvallon (1998), eAs metamorfoses da questão social: uma crõnica do salário de Robert Castel (1998). Ambos tomam como referência para análise a sociedade francesa.

Rosanvallon identifica a questão social como a expressão, criada no final do século XIX, referente às disfunções da sociedade industrial emergente. A "nova questão social", por sua vez, decorre do crescimento do desemprego e do surgimento de novas formas de pobreza. Tem como parâmetro o desenvolvimento e a crise do paradigma keynesiano; do modelo de acumulação e métodos de gestão econômica e social, bem como do Estado Providência e dos esquemas reguladores de proteção social e trabalhista. O que parecia estar ao alcance da sociedade - a 
segurança social - passa, a partir do final da década de 1970, a ficar como um ideal distante.

Castel centra sua análise da nova questão social a partir de sua manifestação por meio do "enfraquecimento da condição salarial" (1998:495), sendo um de seus efeitos, tendo em vista "o desemprego em massa e a instabilidade das situações de trabalho, a inadequação dos sistemas clássicos de proteção para dar cobertura a essas condições, a multiplicação de indivíduos que ocupam na sociedade uma posição de supranumerários, 'inempregáveis', inempregados ou empregados de um modo precário, intermitente" (p.25). Castel entende que o presente é também um efeito de herança do passado e sua memória é necessária para compreender e agir hoje. Por isso utiliza o termo "desfiliação" - como resultante de um processo cujo percurso é preciso ser reconstituído, no sentido de "procurar a relação entre a situação em que se está e aquela de onde se vem, não autonomizar as situações extremas mas juntar o que se passa nas periferias com o que acontece em direçao ao centro" (p.26). Para Castel, esta perspectiva de análise evidencia a posição estratégica ocupada pela" 'zona de vulnerabilidade' porque alimenta as turbulências que fragilizam as situações conquistadas e desfazem os estatutos assegurados". Esta situação de vulnerabilidade vem marcando, ao longo da história, a condição popular com o selo da incerteza e, mais amiúde, com o do infortúnio (p.27).

Esse processo de manifestação do social é caracterizado por Castel pelas suas "metamorfoses", entendidas como "dialética do mesmo e do diferente". Reconhece as diferenças entre a noção de "estabilidade, instabilidade ou exclusão do emprego, inserção relacional, fragilidade dos suportes protetores ou isolamento social" visíveis hoje, assim como na sociedade pré-industrial ou no século XIX. No entanto, tais mudanças, se inscritas no quadro de uma mesma problematização, deixam de representar

9 O autor estabeleceu como indicador para avaliar a coesão de um conjunto social em um dado momento o equilíbrio entre as "zonas", de coesão - identificada como a área de integração e caracterizada pela associação trabalho estável e inserção relacional forte, e de vulnerabilidade - caracterizada como "zona intermediária, instável, que conjuga a precariedade do trabalho e a fragilidade dos suportes de proximidade" (p.24). 
inovações absolutas. Para tal, busca inicialmente mostrar a posição relativa ocupada pelas populações inseridas nas "zonas" e na estrutura social. Utiliza como exemplo os "inúteis para o mundo" que, antes da revolução industrial, representavam-se pelos vagabundos e os "inempregáveis" de hoje. Demonstra, ainda, a identidade nos processos que produzem essas situações, semelhantes em sua dinâmica e distintas em suas manifestações, pois a presença dos "supranumerários" é expressa por aqueles que não conseguiam/conseguem um lugar estável nas formas dominantes de pertencimento comunitário. Apesar disso, o desenvolvimento da história revela um número de "descontinuidades, de bifurcações de inovações que devem ser resolvidas" (p.28). Como exemplo, a condição de assalariado que passa do descrédito ao reconhecimento de principal fonte de renda e de proteções. Contudo, ainda hoje permanece com a conotação de precariedade e de infortúnio.

A questão social como se apresenta hoje, na visão de Castel, a partir do enfraquecimento da condição salarial, tem como um de seus efeitos a exclusão e, devido à sua visibilidade, tem ocupado, nos últimos anos, o primeiro plano, deslocando para a margem da sociedade o que a atinge primeiro no coração - o estatuto do salariado.

Daí a recusa de Castel no uso do termo exclusão, pois este designa "estados de privação" e a sua simples constatação não permite recuperar os processos nos quais as carências ocorrem. Em contraposição, utiliza o termo desfiliação.

Entretanto, na diversidade das análises, pode-se identificar diferentes denominações para o que tem-se reconhecido como exclusão. Demo (1998), em trabalho na qual busca questionar o conceito de exclusão social analisando diversos autores da literatura francesa, identifica em Paugam a exclusão como expressão da angústia de numerosos segmentos da população, "inquietos diante do risco de se ver um dia presos na espiral da precariedade", acompanhando "o sentimento quase generalizado de uma degradação social" (Paugam apud Demo, 1998:17). Para Paugam, "o sucesso da noção de exclusão é que ela põe acento, ao menos implicitamente, sobre uma crise do liame social" (p. 18).

Nesta perspectiva, Paugam reconhece a existência da "nova questão social" por entendê-la numa amplitude que afeta o conjunto da sociedade, 
ameaçadora da ordem social e da coesão dos indivíduos. Distingue três patamares da pobreza:

a) pobreza integrada: "seu nível de vida é baixo, mas permanece fortemente integrada em seus espaços sociais organizados em torno da família e do bairro ou da vila" (apud Demo, p. 30) caracterizada pelo sentido tradicional de pobreza.

b) pobreza marginal: considerada entre pobreza tradicional e exclusão social.

c) pobreza desqualificante: expressa pela exclusão social na qual os pobres vivem um sentimento de "inutilidade social" por estarem fora da esfera produtiva e dependentes das instituições sociais.

Conforme Paugam, portanto, "a pobreza desqualificante é uma relação social para com os 'pobres' e com os excluídos que gera uma angústia coletiva, pois cada vez mais pessoas são consideradas como categorias, e muitos, de situação instável, temem aí decair" (apud Demo, p.30)

Demo localiza em tal afirmação, a qual ele considera uma alegação típica, algumas impropriedades teóricas tais como:

- os excluídos, dialeticamente, fazem parte do sistema, não cabendo vê-los simplesmente como excluídos;

- não é possível imaginar que os excluídos estejam "fora", se se considera que grande contingente da sociedade é atingido pelo risco da exclusão;

- o argumento em torno da angústia coletiva não consistiria em um fenômeno novo na sociedade;

- a "nova questão social", como se quer chamar, "parece ser, assim muito mais o susto da Europa (França) já acostumada a certo bem-estar para as maiorias, ao lado das marcas próprias de uma nova fase do capitalismo" (p.30)

Para Demo, a afirmação de uma crise da "sociedade salarial" implica reconhecer a presença da questão capitalista e, "se o capitalismo está em nova fase, ainda é aquele. Não forja uma nova questão social, mas 'curte', em novo momento a velha exploração capitalista" (idem). 
Para Schnapper, (apud Demo, p. 13) começa a emergir um processo de "desafiliação" ou de desligamento que levaria da precariedade à exclusão. Nesta perspectiva o emprego é decisivo para definir a condição social do indivíduo.

Ainda na análise de Demo, Castel faz uma tentativa de definir os conceitos, chegando a um meio-termo, para quem o início do processo de exclusão ocorre com o fenômeno de "desenraizamento". Em Rosanvallon é identificada a tendência em considerar os excluídos como "não-força".

Wacquant (apud Demo, p. 29) identifica a análise crítica do termo "underclass", referente aos excluídos nas sociedades capitalistas avançadas, como nos Estados Unidos, apontando para "pobres do gueto", conceito que para Demo denota um contexto injusto de acusação moralista típico da cultura norte-americana. Apesar de o conceito não ter uma propriedade teórica e empírica consistente, Demo destaca "o nascimento de um termo vago para realidades relativamente novas e, de outro, a estigmatização delas em tom depreciativo".

Para Fassin, "se considerarmos as tipologias simbólicas pelas quais as sociedades se representam para si mesmas, é notável que, no decorrer do período recente, o desenvolvimento da pobreza urbana deu lugar a três figuras diferentes - exclusão na França, underclass nos Estados Unidos, marginalidad na América Latina - que reconduzem a três configurações do espaço social - dentro/fora, alto/baixo, centro/periferia, respectivamente" (apud Demo, p.27). Fassin considera que, em termos de exclusão social, a França se aproxima da América Latina. Para Demo, esta referência "mais do que chamar a atenção para a gravidade do problema, trai por não se tratar propriamente de uma 'nova questão social' mas de modos específicos de seu agravamento na história do capitalismo" (p.29).

O que podemos verificar são diferentes argumentações no tratamento da exclusão social. Nessas o termo é visto como um fenômeno sempre presente na história social ou, a partir de seu agravamento e extensão, no "bojo do processo de globalização da economia e da desregulação do trabalho e da proteção social configurando a 'nova questão social'". 
Donzelot (1998), ao abordar a exclusão social, alerta para a necessidade de desconfiarmos da familiaridade das palavras, da segurança linear que elas conferem à ordem das coisas, e à natureza dos problemas aos quais somos confrontados. "A luta contra a exclusão mascara uma mutação das formas de intervenção social à qual assistimos após 20 anos [...] assistimos à emergência de um novo modo de intervenção social visando desta vez, não mais aos 'esquecidos do progresso', mas às vítimas da nova ordem socioeconômica" (p. 178). As vítimas desta nova ordem constituíam-se de uma população que, antes considerada "normal" passa, hoje, a se "tornar inútil" a esta mesma ordem.

Conforme Donzelot (1998), para se compreender essa mutação dos modos de intervenção - é necessário relacioná-la com mudança de significado da questão social produzida nessa conjuntura. Sinteticamente, essa modificação pode ser assim apresentada:

a) a passagem "de uma questão à outra" deixa transparente que, na visão clássica, o sentido da exclusão é político ${ }^{10}$ à medida que mesmo se reconhecendo a capacidade política dos cidadãos, esta soberania não é acompanhada da transformação da condição social dos trabalhadores. Apesar da proclamação do direito ao trabalho, sua concretização "revelou uma contradição entre a garantia da liberdade e a aplicação sistemática do direito ao trabalho a todos" (p. 179).

Conforme Rosanvallon (1998), o temor era que, ao garantir o direito do trabalho o Estado estaria "obrigado a dar, a cada um, um emprego correspondente à sua qualificação [...] passará a ser [um Estado] industrial, comerciante, produtor em pequena ou grande escala onerado por todas as necessidades, será levado irremediavelmente a deter o monopólio de todas as indústrias ou pelo menos a regulamentá-las de forma integral" (p.121). Reconhecia-se, assim, que o Estado poderia dar assistência e que esta não deveria ser chamada de direito. Conforme Rosanvallon, "sim ao desenvolvimento de uma política social, não ao reconhecimento de um direito social" (idem). Havia também aqueles que consideravam importante priorizar o reconhecimento do direito social, mesmo que o Estado não o colocasse em prática em suas políticas. O caráter político

${ }^{10}$ A esse respeito ver também Généreux, 1999. 
da questão revelava problemas na relação entre o socialismo e a democracia. Conforme Rosanvallon, "a reflexão sobre as condições da passagem de uma assistência passiva (a distribuição de socorros) a uma forma ativa de inserção social pelo trabalho nunca foi desenvolvida a fundo nos países ocidentais" (p. 124). A reflexão sobre o direito do trabalho, um século e meio depois da Revolução de 1848, volta a ser atual.

É em meados dos anos 70, afirma Donzelot, que aparece a "nova questão social" revelando-se como efeito da desconexão entre o aparelho de ação pública e a sociedade. Denuncia-se a "impotência do Estado, sua incapacidade de lutar contra o aumento do desemprego, contra a relegação das periferias, contra a nova pobreza, contra a dualização da sociedade" (1998:180).

Diante das características da "nova questão social" Donzelot destaca três elementos que estão em conformidade com os elementos da democracia formal e nos quais, ao mesmo tempo, seus conteúdos se contradizem:

- aparecimento de não-forças sociais - segmentos excluídos da ordem socioeconômica e incapazes de se dotar de uma representação, o que os tornaria uma força social;

- a dificuldade de representação política apóia-se no surgimento de uma descontinuidade entre as preocupações da ação e aquelas de parte da população. Observa-se uma tendência à representação das nãoforças de uma maneira demagógica isto é, "jogam as cartas da representação político-demagógica contra a lógica da ação", o que significa "apelar à soberania do indivíduo em detrimento da responsabilidade do cidadão";

- o tema da democracia formal poderia denunciar o caráter nacional da representação a valorizar a fraternidade internacional da classe operária contra os interesses rivais das burguesias nacionais, assim como a tecnocracia parece se prestar a valorizar as imposições mundiais e econômicas contribuindo para que se destrua a parte mais prejudicada da sociedade.

Para Donzelot, passa-se de uma crise da representação à crise da ação, do sentimento de exclusão política pela condição de sujeição à ordem 
socioeconômica; exclusão social produzida pela ordem socioeconômica, e que somente encontra meios pela manifestação desesperada da soberania política, (p. 182).

A transformação das intervenções diante da exclusão devem ter como referência a transformação da natureza da questão social.

b) A passagem "do social moderno ao social pós-moderno", período no qual se desenvolvem os conceitos de solidariedade. O primeiro momento da questão social clássica, cujo sentimento de exclusão manifestase de forma política, está caracterizado pela ausência de reconhecimento da classe operária diante das instituições da República. O sentimento da classe operária com a sociedade é de insolidariedade, pois a solidariedade só existe entre seus membros.

A integração da classe operária por meio das políticas sociais tinha como referência a teoria comunitária cujo "modelo do elo social deve se sustentar sobre o contrato voluntário, unindo os indivíduos um a um e cada um à sociedade" (p. 183). No entanto, esta concepção deixava as massas sem controle de sua vontade própria contra o poder. Passou-se, então, a outra concepção do elo social, construído a partir do conceito de solidariedade que marcará o social moderno. Juntamente com a sociedade industrial apareceria uma nova solidariedade, chamada por Durkheim de orgânica. As intervenções sociais em atenção à exclusão foram construídas com base na idéia de que o papel da República era, de um lado, "defender o indivíduo contra os riscos que o faziam correr desta sociedade pelo fato da divisão social do trabalho" e, de outro, "de proteger a sociedade contra o indivíduo que a ameaça devido a seus comportamentos antisociais" (p. 184).

Tais intervenções representam as origens da proteção social expressas pela promoção do direito aos socorros, pensado em sua oposição à obrigação de seguro e, como direito social só acessível "aos que já estão quase fora-do-social", nessa zona de assistência isolada dos circuitos de trocas entre os indivíduos autónomos. O direito não deve tocar a zona de vulnerabilidade, aquela da precariedade do trabalho das insuficiências da condição salarial (Castel p.382). 
A intervenção do poder público só se dá em casos limites, atípicos em relação à condição trabalhadora. Não há responsabilidade coletiva diante das desventuras do povo.

A solidariedade, de fato, consiste "em mobilizar o direito para uma certa redistribuição dos bens sociais e uma certa redução das desigualdades" (p.380) expresso na noção do detentor do direito materializado na aposentadoria no seguro.

Diferentemente da situação anterior, o seguro possibilita sua aplicação a uma infinidade de situações, "o princípio da cobertura do risco não depende da natureza do risco coberto'" (p.384). Apesar de, no início, o seguro estar muito longe de promover uma seguridade generalizada já que "as primeiras aplicações do seguro obrigatório foram limitadas às categorias da população ameaçadas de decadência social" (idem), o risco coberto, de fato, é o risco de passar de uma situação vulnerável para uma situação miserável, o que não possibilita a ruptura com a situação anterior.

Para o enfrentamento dessas questões é essencial a compreensão das novas relações, no início do século XX, entre trabalho, seguridade e propriedade. $\mathrm{O}$ advento do seguro sanciona, assim, o reconhecimento do caráter irreversível da estratificação social nas sociedades modernas e o fato de que possa ser fundada na divisão do trabalho e não mais apenas na propriedade (Castel, p. 403).

Somente em 1945 é que o seguro obrigatório torna-se princípio de cobertura generalizada contra os riscos sociais. Entretanto, sua realização depende do equilíbrio entre interesses divergentes. Nessa época tem-se uma abertura decisiva em relação aos direitos sociais.

Depois dos anos 70 a ordem socioeconômica passa a ser a causa da exclusão, pois as filas de desempregados estão cheias de "normais úteis" (Donzelot, p. 186). Inúmeras são as medidas adotadas nos anos 80 para enfrentamento deste novo quadro. Curiosamente, o "social pósmoderno" é desenhado a partir de uma recuperação da concepção do social anterior ao "social moderno", como delineia Donzelot:

- retorno à concepção comunitária do social pela valorização do local; trata-se de reforçar o elo social; 
b) renascimento da concepção contratual do elo social, a idéia da inserção ampara-se no retorno ao contratual. É a passagem da indenização à inserção.

c) O sentimento de exclusão ligado à questão social clássica estava relacionado ao "déficit de representação da sociedade real na sociedade política" (Donzelot, p. 187), tendo sido necessário o desenvolvimento de formas de consultas das forças sociais de forma a integrá-las no processo de decisão, apropriada à reconciliação da sociedade com o poder político. Entretanto, no início dos anos 70, a "consultação" perde sua credibilidade dando lugar à formulação da implicação/responsabilização das estruturas comunitárias. Tal fórmula equivale à intervenção do Estado por meio da atribuição e não mais de ocupação desta posição. Donzelot analisa este momento como uma necessidade no sentido de que o Estado já é frágil para se impor e não pode agir sem procurar as instâncias que se associam a ele; assim, como uma oportunidade à medida que seus meios denunciem, maior é a possibilidade de reunir atores.

d) De uma época à outra, final do século XIX à atualidade, assistimos às mutações "do Estado de progresso ao Estado animador" (na análise de Donzelot); do Estado provedor a regulador, enfim, do Estado defensor da sociedade como um todo, com base na repartição dos frutos da solidariedade e a contribuição de cada um para o referido progresso; ao Estado que "fez-se o agente deste progresso em nome da mundialização da economia que clama por uma modernização nacional" (p. 190).

A idéia do "Estado animador" emerge na década de 1980 no sentido de reorientar-se na função de preservação da coesão social da nação, caracterizando-se não mais como o "tutor da sociedade, mas mobilizador de seus recursos" (p. 191) na luta contra a dessocialização.

Vimos a instalação do Estado Social desdobrada em três direções, conforme Castel (p. 181):

- a garantia de uma proteção social generalizada, com a instauração da seguridade social em 1945;

- manutenção dos grandes equilíbrios e condução da economia Estado como regulador da economia; 


\section{SER SoaAL 6}

- busca de diferentes parceiros implicados no processo de crescimento.

Nesta última, o Estado, no seu papel regulador, atua sobre a relação entre os parceiros sociais, nas negociações "sobre uma base contratual, com a iniciativa ou a arbitragem do Estado, os interesses divergentes dos empregadores e dos assalariados" (p.489).

A trajetória marcada pela "poderosa sinergia entre o crescimento econômico com seu corolário, o quase-pleno-emprego, e o desenvolvimento dos direitos do trabalho e da proteção" (p.493) foi interrompida. A característica mais inquietante da situação atual é o reaparecimento de um perfil de trabalhadores sem trabalho, os quais, conforme Castel, "literalmente, ocupam na sociedade um lugar de supranumerários, de inúteis para o mundo" (p.496).

O quadro torna-se mais complexo à medida que a degradação da condição do trabalhador passa a alimentar o aumento do número dos excluídos. É preciso não esquecer que "a exclusão não é um estado social determinado, ela resulta de um processo" (Rosavallon, p. 80). Um processo marcado pela internacionalização das economias capitalistas cujas características -a integração dos mercados financeiros mundiais, o crescimento do comércio internacional, a presença de empresas transnacionais - contribuem para diminuição do espaço para operação de políticas públicas.

Conforme Dupas (1999), "o sentimento de desamparo é reforçado pelo fato de o Estado, desde o pós-guerra identificado como guardião das garantias individuais, estar passando por forte reestruturação e rediscutindo essa função" (p. 16).

E no contexto, portanto, de globalização e de alteração no papel do Estado que emerge a "nova questão social" cujos efeitos podem ser encontrados no "desemprego estrutural, aumento da pobreza e da exclusão social, precarização e casualização do trabalho e desmonte de direitos sociais edificados há mais de um século" (Pereira, 1999a: 47). 
Diante desse contexto importa questionar: que perspectivas e alternativas vêm se desenhando no campo das políticas sociais? Qual o peso e o papel do Estado na garantia da seguridade social? Com que cenários haveremos de conviver no futuro? Estaria o Welfare State caminhando para o fim?

\section{Forma política de enfrentamento: Welfare Pluralism?}

O mundo marcado pelo desemprego e pela exclusão, pela crescente diferença entre ricos e pobres no interior do mundo rico, bem como entre o mundo rico e o mundo pobre, tem se constituído na principal contradição do sistema capitalista da atualidade, o que compromete seriamente a imagem do Welfare Sate social democrata, como parte integral que é desse sistema.

O colapso da social-democracia no contexto de uma crise sem precedentes e a incapacidade de sua revitalização nesse contexto têm possibilitado que forças conservadoras reaglutinem-se política e ideologicamente em torno de princípios liberais em combate à feição democrática que marcou este século (Fleury, 1994).

De forma sintética, o argumento utilizado pelas forças conservadoras é o de que o Welfare State tem usurpado a possibilidade de livre aplicação dos princípios do mercado e tem sido a causa principal da estagnação das economias ocidentais, por meio dos seus efeitos de redistribuição. Nesse sentido, passam a impor a idéia do Estado mínimo, cujos objetivos políticos consistem em cortar gastos públicos; ampliar o escopo do setor privado, a fim de melhorar as opções e retirar a carga do governo; destinar aos pobres os gastos estatais remanescentes, passando de serviços universais a seletivos; reduzir a tributação, a fim de liberar as empresas, melhorar as opções e apoiar as atividades privadas e voluntárias como substitutas dos serviços previdenciários estatais (Taylor-Gooby, 1989).

A "receita" neoliberal está contida no conjunto de reformas dos sistemas de proteção social, orientadas para a sua privatização, 
descentralização, focalização e criação de programas sociais e de emergência, dirigidos à população ou grupos carentes. Esta "receita" ressuscita, na opinião de Pereira (1994), antigos procedimentos de ajuda mútua, com base na solidariedade e sob o rótulo do welfare pluralism ou "divisão social do bem-estar", já previstos por William Beveridge em seus relatórios de 1944 e 1948, época em que as instituições da família, da vizinhança e da comunidade podiam oferecer alternativas às funções sociais do Estado. Hoje os tempos são outros e a estrutura da família também.

Com base nesse novo quadro de divisão de responsabilidades sociais e de crescente envolvimento da sociedade é que diversos autores vêm analisando o que está sendo chamado de modelo pluralista de bem-estar.

O que é o pluralismo de bem-estar?

O pluralismo de bem-estar ou bem-estar misto consiste, em tese, numa ação compartilhada entre as três esferas da sociedade moderna, na provisão de bens e serviços que atendam às necessidades humanas básicas - o mercado, o Estado e a sociedade. Esta concepção estabelece uma divisão de responsabilidades na esfera do bem-estar, bem como de redistribuição de funções entre Estado, mercado e sociedade; isto é, tais responsabilidades devem ser postas em um novo equilíbrio. Nesse sentido, o Estado não mais se constitui no principal provedor de bens e serviços, os quais devem ser compartilhados por quatro setores diferentes: o oficial, o voluntariado, o comercial e o informal.

Abrahamson (1995) faz referência a um modelo triangular/tripartite, segundo o qual cada uma das pontas do triângulo detém recursos específicos: o mercado detém o capital; o Estado, o poder; e a sociedade, a solidariedade. O capital e o poder, nas palavras de Habermas (1987), pertencem ao mundo do sistema (dominado pela razão instrumental) que, no processo de modernização capitalista acabou dominando e "colonizando" o "mundo da vida"; neste espaço existe uma razão comunicativa que se opõe à "reificação" e "colonização" exercida pelo "sistema". 
Nesse modelo, tanto o mundo da vida quanto o sistema são atravessados pelas dimensões do público e do privado. No mundo do sistema, o público é o Estado, o privado é a economia. No mundo da vida, o público é a participação política dos cidadãos, e o privado é a família (Vieira, 1997:56). Estas dimensões se relacionam mediante trocas, que se tornam possíveis pelos meios de controle - dinheiro e poder.

Estão implícitas nesta reflexão não só a crítica às políticas sociais de pós-guerra (reconhecidas como paternalistas) como também uma proposta de mudança no rumo desta política, que deve ser realizada mediante programas autônomos e descentralizados com base na sociedade civil. Isto, se pensarmos a sociedade como o campo onde se desenvolvem capacidades que possibilitem às pessoas desempenhar um papel nas escolhas políticas e econômicas, com vistas à preparação do terreno para um caminho social de desenvolvimento, que pode complementar o político e o econômico (Wolfe, 1991:46).

No entanto, na perspectiva do modelo triangular, é preciso questionar: por que a sociedade civil é importante? Que papel deve desempenhar no processo de desenvolvimento? Quais devem ser os objetivos do desenvolvimento?

$\mathrm{Na}$ busca de respostas a essas questões, encontramos que a importância da sociedade - campo da vida social, como o bairro ou a localidade - está na possibilidade de executar políticas públicas mais próximas das pessoas, das realidades onde vivem. Com base neste argumento, o discurso da descentralização tem sido utilizado pelos mais diferentes matizes políticos. O Relatório de Desenvolvimento Humano de 1993 afirma que "La descentralizcición dei poder - de las capitales a las regiones, las ciudadesy los pueblos - pode ser una de las mejores formas de conferir poder ai pueblo, promover la participación dei público y aumentar la eficiência" (p.6).

Quanto ao papel que desempenha, é expresso por um crescimento, em todo o mundo, de atividades fora do alcance formal do Estado. Há uma expansão das atividades "associativas civis", cuja novidade consiste na capacidade de inclusão de demandas, a qual já tem sido considerada uma área estratégica na economia. O chamado Terceiro Setor, conforme 
constatação de Drucker, analisado por Gohn (1998:16), foi o que mais cresceu, mais movimentou recursos, gerou empregos, bem como foi o mais lucrativo na economia norte-americana nos últimos 20 anos. Como afirmam Pereira e Grau,

... a principal razão para recorrer às entidades serafins lucrativos não é porque sejam mais eficientes na provisão de recursos do que poderia ser qualquer outra entidade, mas sim porque permitem desenvolver papéis que nem o Estado nem o mercado podem cumprir. E assim como a confiança, a dedicação, a solidariedade constituem papéis que lhes imprimem uma especificidade em relação ao setor lucrativo, a flexibilidade, a experiência especializada e a habilidade para chegar a clientes difíceis de alcançar são exibidas como algumas das maiores vantagens que o setor não-lucrativo ou público não-estatal teria sobre o setor público-estatal (1999:34).

Partindo desta análise, que perspectiva podemos identificar no modelo triangular/tripartide, quanto à sociedade civil?

A ênfase na sociedade como principal agente de bem-estar tem conquistado adesões nas mais diferentes correntes ideológicas, por meio de discursos/bandeiras sobre a emancipação dos pobres da tutela do Estado; a descentralização do poder; o incentivo à participação popular; a divisão de custos; a diluição da fronteira entre o público e o privado; a inauguração de uma visão holística de bem-estar, entre outros. No entanto, esta conotação positiva à participação pode estar encobrindo a tendência privatizante que tem sido utilizada nas duas últimas décadas.

A ênfase à sociedade constitui, na verdade, uma estratégia para diminuir a ação estatal na área de bem-estar e, com isso, reduzir gastos públicos. Em nome da descentralização, da parceria, da solidariedade ocorre uma retração do Estado (Stein, 1997). Por isso, é preciso distinguir entre fins e meios da assistência, entre privatização e oferta de serviços.

A análise pioneira de Titmuss sobre a "divisão social do bem-estar", como informa Míshra, refería-se à proteção estatal, fiscal e ocupacional", e esta se distancia muito das "avaliações decididamente positivas da 'mistura 
providencial' preconizada pelos pluralistas do bem-estar hoje em dia" (1995:103).

$\mathrm{O}$ autor considera que as mudanças recentes no Estado de BemEstar, principalmente nos países neoconservadores, têm sido vistas como mudanças na forma pela qual a assistência é prestada. Muitas vezes, alerta o autor, o papel reduzido do Estado na proteção é encarado positivamente por resultar numa forma de assistência mais descentralizada.

A esse respeito, Johnson (1990) chama a atenção para o crescimento das novas iniciativas sociais como, de certa forma, das respostas às supostas falhas na atuaçao dos Estados de bem-estar e, ainda, para o fato de que os governos estão animando e apoiando as novas iniciativas, como parte integrante das políticas de pluralismo de bem-estar (1990:87). E, estas, tornar-se-ao cada vez mais importantes, à medida que se tornarem maiores as restrições fiscais e políticas de desenvolvimento executadas pelo Estado.

Esta fórmula pode deslocar de um setor para outro a responsabilidade de providenciar, podendo o Estado desresponsabilizarse do papel de provedor de bens e serviços, passando a estimular/encorajar empresários, grupos voluntários, familiares e outras esferas nãogovernamentais para aumentarem seus esforços nesse processo (Mishra, 1990:102).

Nessa perspectiva, confígura-se o ideal de substituição do Estado de bem-estar social pelo de bem-estar pluralista. Para Giddens, "no lugar do Welfare State deveríamos considerar o Estado de investimento social, operando no contexto da sociedade de Welfare positivo ${ }^{12}$ [...] para o qual os próprios indivíduos e outras instituições além do governo contribuem - e que é funcional para a geração da riqueza (1999:127).

Assim, a sociedade - envolvendo a família, a vizinhança, os grupos de amigos - tem sido cada vez mais mobilizada e responsabilizada para resolução de problemas relacionados à pobreza e à exclusão social.

11 O autor considera necessário torná-lo "positivo", em contraposição ao foco negativo contido no Relatório de Beveridg, quando, em 1942, "declarou guerra à Carência, à Doença, à Ignorância, à Sordidez e à Ociosidade" (idem). 
A família são devolvidos os encargos antes assumidos pelo Estado, como o cuidado com crianças, idosos, portadores de deficiências.

Da mesma forma, podem ser encontrados estímulos e apoios nos Relatórios de Desenvolvimento Humano/Pnud, que desde o início desta década vêm sinalizando sobre o "novo paradigma": o local e o popular.

O Informe de 1993 dedica especial atenção à participação popular e à descentralização. O relatório de 1999 está "...claramente a favor do poder da globalização para trazer os benefícios econômicos e sociais para a sociedade" (Brown, 1999). Do conjunto de recomendações governação e mercados - para mudar o modo como a sociedade está organizada, o Relatório manifesta-se mais sobre a "governança" acreditando que "os governos e parceiros da sociedade civil, o sector privado e outros estão a formar coligações funcionais através de fronteiras geográficas e das linhas políticas tradicionais, para conduzir a política pública ao encontro das aspirações de uma cidadania mundial' (idem).

Entre as diversas indicações, o relatório recomenda "redistribuir os custos e responsabilidades do apoio social - pelas famílias, Estado e empresas", e reconhece que "a família, actualmente, é um pequeno estado providência" (Pnud, 1999:80).

Há, ainda, entre os autores e agentes envolvidos com esta temática, uma diversidade de proposições alternativas quanto ao Estado ideal para o enfrentamento da "nova questão social": estado "animador", "possibilitador", "rede", "del bien obrar", "serviço", entre outros. No entanto, é preciso ressaltar que a proposta de welfare pluralism em evidência "não é uma simples variação [...] das noções de Welfare State e Social Welfare do pós-guerra" (Pereira, p. 11); seus pressupostos são diferentes, isto é, privilegiam o setor privado e, por isso, vão muito além da simples questão de decidir quem pode, comparativamente, ser mais eficiente na promoção do bem-estar.

A preocupação relacionada à tutela do Estado contraria a compreensão do bem-estar como direito do cidadão e dever do Estado, 
pois este é o único ator que detém a autoridade coativa, para garantir esse direito de forma desmercadorizada. Para isso, é necessário reconhecer a existência de uma "arena real de conflitos de interesses na distribuição de recurso entre Estado e sociedade" (idem), onde a sociedade possa, de fato, estar desenvolvendo seu papel crítico na definição das tendências da política social. Caso contrário, reconhecer este espaço somente como espaço da solidariedade estaria contribuindo para a negação dos direitos de cidadania.

Por esse ponto de vista, o pluralismo de bem-estar pode não ser nocivo, se inserido numa proposta institucional, na qual o Estado tenha a responsabilidade da manutenção dos níveis básicos nacionais em termos de rendimentos, saúde, habitação, educação, assistência social. Caso contrário, teríamos uma proposta pluralista/residual, aquela com a retração da intervenção do Estado, que tem se caracterizado como uma tendência. Como afirma Mishra, os países neoconservadores assistiram a um deslocamento da política institucional para uma dimensão residual, à medida que abandonaram o sistema de prestação de serviços centralizados ou estatal, em favor de um sistema descentralizado e privatizado.

Por seu turno, Doyal e Gouhg (1994) argumentam em favor de uma estratégia dual, isto é, uma política que busque a otimização da satisfação das necessidades sem deixar de incorporar tanto a generalidade do Estado como a particularidade da sociedade civil.

\section{Considerações finais}

Do exposto, infere-se que a (nova) questão social manifesta-se como fenômeno histórico cujos elementos fundamentais permanecem intocados e inalterados: a acumulação de riqueza por uns em detrimento da expropriação e destituição de muitos outros, os pobres, os pauperizados, os excluídos, que parecem sem lugar na cena histórica.

No entanto, são estes mesmos excluídos, expropriados e destituídos que conseguem ultrapassar, através de suas lutas, estigmas como vagabundo, vadio, mendigo, colocando-se como trabalhadores, 
desempregados, bradando para todos o horror de uma tragédia onde os sofisticados meios de produção impõem a eles a condição de "inempregáveis".

As estratégias de enfrentamento comportam desde o Estado provedor de bens e serviços a um Estado minimalista, responsabilizando a sociedade por meio de suas redes de solidariedade pelo enfrentamento da questão social.

Ao Estado contemporâneo, cuja soberania como Estado-Nação vê-se esvaziada, são postos desafios como a garantia de sociedades justas, mas segundo critérios utilitaristas do mercado e voluntaristas da sociedade e, portanto, sem os meios cívicos para exercer essa garantia.

\section{BIBLIOGRAFIA}

ABRAHAMSON, Peter. Welfare Pluralism: Para um novo consenso na política social europeia. Tradução de Potyara Amazoneida P.Pereira. NEPPOS/CEAM/UnB. Brasília, 1995.

CASTEL, R. As metamorfoses da questão social uma crónica do salário. Trad. D. Poleti. Petrópolis, RJ: Vozes, 1998.

CASTELLS, M. "O Estado-rede e a reforma da administração pública". Reforma Gerencial. Revista do Ministério da Administração Federal e Reforma do Estado, n 2, Jul. 1998 p. 27-28.

El futuro dei Estado del Bienestar en la sociedade informacional. GINER, Salvador e SARAS A, Sebastián (eds.) Buen Gobierno y Política Social. Barcelona: Editorial Anel, S. A 1997. P. 173-189.

DEMO, Pedro. Charme da exclusão social. Campinas-SP : Autores Associados, 1998 (coleção polêmicas de nosso tempo; 61).

DONZELOT, Jacques. As transformações da intervenção social face a exclusão. SER SOCIAL.3 Tradução de Ivanete S. Boschetti Ferreira e Denise Bomtempo B. de Carvalho. Brasília, 1998, p. 177-192.

DOYAL, Len e GOUGH, Ian. Teoria de las necesidades humanas. Barcelona: ICARIA: FUHEM, D. L. 1994. 
DRAIBE, Sônia. As políticas sociais brasileiras: diagnósticos e perspectivas. IPEA/IPLAN. Para a década de 90: Prioridades e perspectivas de Políticas Públicas. Brasília, março 1990. RI-67.

DUPAS, Gilberto. Economia global e exclusão social: pobreza, emprego, estado e ofuturo do capitalismo. São Paulo: Paz e Terra, 1999.

ESPING-ANDERSEN, Gosta. O futuro do Welfare State na nova ordem mundial. Revista Lua Nova. São Paulo, n 35, 1995 p.73-111.

- As três economias políticas do Welfare State. Revista Lua Nova. São Paulo, n²4,Set. 1991, p.85-116.

FLEURY, Sônia. Estado sem cidadãos: Seguridade Social na América Latina. Rio de Janeiro : FIOCRUZ, 1994.

GÉNEREUX, Jacques. O Horror Político: O Horror não é económico. Tradução Eloá Jacobina. $2^{\text {a }}$ ed. Rio de Janeiro: Bertrand Brasil, 1999.

GIDDENS, Anthony. A terceira via. Reflexões sobre o impasse político atual e o futuro da social democracia. Tradução de Maria Luiza X. de A. Borges. Rio de Janeiro : Record, 1999.

GOHN, Maria da Glória. O novo associativisno e o Terceiro setor. Serviço Social e Sociedade. São Paulo : Cortez Editira, n.58. Ano XIX, nov.1998

GOMES, Angela M. de C. Burguesia e Trabalho: Política e legislação social no Brasil 1917-1937. Rio de Janeiro : Campus, 1979.

GOUGH, Ian. Economia Política del Estado del bienestar. Madrid: H. Blume Ediciones, 1982.

HABERMAS, Jurgen. A nova intransparência: a crise do Estado de bemestar e o esgotamento das energias utópicas. Novos Estudos CEBRAP, São Paulo, n $18,1987$.

HARVEY, David. A condição pós-moderna. São Paulo : Loyola, 1993.

INFORME SOBRE DESARROLLO HUMANO 1993. Madrid : PNUD/ CIDEAL, 1993.

JOHNSON, Norman. El Estado de Bienestar en transición. La teoria y la práctica del pluralismo de bem-estar. Madrid, Ministério de Trabajo Y Seguridad Social. Espana, 1990. 
MISHRA, Ramesh. O estado providência na sociedade capitalista: Políticas públicas na Europa, América do Norte e Austrália. Oeiras: Celta Editora, 1995.

OFFE, Claus. Algumas contradições do Estado Social moderno. In. Trabalho e Sociedade: Problemas estruturais e perspectivas para o futuro da "Sociedade do Trabalho". Rio de Janeiro: Tempo Brasileiro, 1991, V.II.

- Trabalho e sociedade: problemas e perspectivas para o futuro da sociedade do trabalho. Trabalho e Sociedade. Rio de Janeiro: Tempo Brasileiro, 1989, v.I.

PEREIRA, Luiz Carlos Bresser e GRAU, Nuria Cunill. Entre o Estado e o Mercado: O público não-estatal. (orgs.) O público não-estatal na reforma do Estado. Rio de Janeiro : Editora Fundação Getúlio Vargas, 1999, p.15-48.

PEREIRA, Potyara, A.P. A metamorfose da questão social e a reestruturação das políticas sociais. Capacitação em Serviço Social e Política Social: Módulo 1: Crise Contemporânea, Questão Social e Serviço Social. Brasília: CEAD, 1999, p.47-58

- Concepções e propostas de políticas sociais em curso: tendências, perspectivas e consequências. Brasília, NEPPOS/ CE AM/UnB, 1994a.

- O Serviço Social e a nova (des)ordem mundial. Brasília, NEPPOS/CEAM/UnB, 1994b

- Centralização e exclusão social: duplo entrave à Política de Assistência Social. In: SER SOCIAL.3 Brasília, 1998, p.119-121.

PIERSON, Christopher. Sobre a crise do welfare state. Trad. de Potyara A. P. Pereira, do original, Beyond the welfare state? Cambridge: Polity Press, 1991.

RELATÓRIO DE DESENVOLVIMENTO HUMANO 1999. Programa das Nações Unidas para o desenvolvimento (PNUD) Lisboa: Trinova Editora. 1999. 


\section{QUESTÃO SOCIAL E SERVIÇO SOCIAL}

STEIN, Rosa Helena. A descentralização como instrumento de ação política e suas controvérsias (revisão teórico-conceitual). Serviço Social e Sociedade. São Paulo: Cortez, n 54, Jul. 1995, p.75-96.

TAYLOR-GOOB Y, P. Welfare, hierarquia e a "nova direita"na era Thatcher. Revista Lua Nova. São Paulo, n.24, set.1991.

VIEIRA, Liszt. Cidadania e Globalização. Rio de Janeiro : Record, 1997.

WOLFE, Alan. Três caminhos para o desenvolvimento: mercado, estado e sociedade civil. A democracia como proposta. Rio de Janeiro: IBASE, 1991. 